UC-420

\title{
FUSION TECHNOLOGY DEVELOPMENT
}

\author{
ANNUAL REPORT TO THE \\ U.S. DEPARTMENT OF ENERGY
}

OCTOBER 1, 1997 THROUGH SEPTEMBER 30, 1998

\author{
by
PROJECT STAFF
}

Work supported by

U.S. Department of Energy

under Contract No. DE-AC03-98ER54411 


\section{DISCLAINER}

This report was prepared as an account of work sponsored by an agency of the United States Government. Neither the United States Government nor any agency thereof, nor any of their employees, makes any warranty, express or implied, or assumes any legal liability or responsibility for the accuracy, completeness, or usefulness of any information, apparatus, product, or process disclosed, or represents that its use would not infringe privately owned rights. Reference herein to any specific commercial product, process, or service by trade name, trademark, manufacturer, or otherwise, does not necessarily constitute or imply its endorsement, recommendation, or favoring by the United States Government or any agency thereof. The views and opinions of authors expressed herein do not necessarily state or reflect those of the United States Government or any agency thereof.

This report has been reproduced directly from the best available copy

Available to DOE and DOE contractors from the Office of Scientific and Technical Information P.O. Box 62

Oak Ridge, TN 37831

Prices available from (615) 576-8401, FTS 626-8401

Available to the public from the National Technical Information Service

U.S. Department of Commerce 5285 Port Royal Road Springfield, VA. 22161

Cover Photo: ARIES-ST ramp-up scenario. 


\section{DISCLAIMER}

Portions of this document may be illegible in electronic image products. Images are produced from the best available original document. 


\section{CONTENTS}

1. FUSION TECHNOLOGY DEVELOPMENT OVERVIEW …..................................

2. FUSION POWER PLANT DESIGN STUDIES ..................................................... 3

3. PLASMA INTERACTIVE MATERIALS ............................................................ 5

4. RADIATION TESTING OF ITER MAGNETIC COIL …......................................... 7

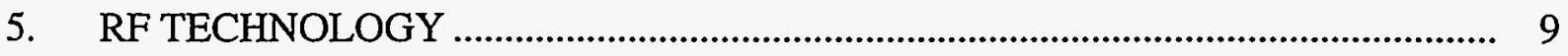

6. ADVANCED LIQUID PLASMA-FACING SURFACES ...................................... 11

7. ADVANCED POWER EXTRACTION STUDY …................................................... 13

\section{LIST OF FIGURES}

2-1. ARIES-ST ramp-up scenario

4

3-1. Measured erosion rate of $\mathrm{Be}, \mathrm{V}, \mathrm{Mo}$ and $\mathrm{W}$, at a heat flux of $0.7 \mathrm{MW} / \mathrm{m}^{2}$ and $\mathrm{T}_{\mathrm{e}}=45-70 \mathrm{eV}$ 
Section 1 FUSION TECHNOLOGY DEVELOPMENT OVERVIEW 


\section{FUSION TECHNOLOGY DEVELOPMENT OVERVIEW}

The overall objective of the General Atomics (GA) fusion technology development program is the advancement of the knowledge base needed for next-generation fusion experiments, and ultimately for an economical and environmentally attractive fusion energy source. To achieve this objective, we carry out fusion systems design studies to evaluate the technologies and materials needed for next-step experiments and power plants, and we conduct research to develop basic and applied knowledge about these materials and technologies. GA's fusion technology development program derives from, and draws on, the physics and engineering expertise built up by many years of experience in designing, building, and operating plasma physics experiments. Our technology development activities take full advantage of the current DII-D program and facility.

The following sections summarize GA's FY98 work done in the areas of Fusion Power Plant Design Studies (Section 2), Plasma Interactive Materials (Section 3), Radiation Testing of ITER Magnetic Coil (Section 4), RF Technology (Section 5), Advanced Liquid Plasma Facing Surfaces (Section 6), and Advanced Power Extraction Study (Section 7). Our work in these areas continues to address many of the issues that must be resolved for the successful construction and operation of next-generation experiments and, ultimately, the development of safe, reliable, economic fusion power plants.

The work was supported by the Office of Fusion Energy Sciences, International and Technology Division, of the U.S. Department of Energy. 

Section 2

\section{FUSION POWER PLANT DESIGN STUDIES}




\section{FUSION POWER PLANT DESIGN STUDIES}

Several items related to the analysis of the ARIES-ST (Spherical Torus) plasma were examined, and a number of suggestions were made concerning possible improvements in performance. These included specification of a reference plasma equilibrium, examination of three possible schemes for plasma initiation, development of a detailed scenario for ramp-up of the plasma current and pressure to its full, final operating values, an assessment of the requirement for electron confinement, and several suggestions for divertor heat flux reduction.

The reference equilibrium was generated using the TOQ code, with the specification of a $100 \%$, self-consistent bootstrap current. The equilibrium has $\beta=51 \%, 10 \%$ below the stability limit (a margin specified by the ARIES-ST study). In addition, a series of intermediate equilibria were defined, corresponding to the ramp-up scenario discussed below.

Three schemes were examined for noninductive plasma initiation. These are helicity injection (HICD), ECH-assisted startup, and inductive startup using only the external equilibrium coils. HICD startup experiments have been done on the HIT and CDX devices. ECH-assisted startup has been demonstrated on CDX-U and DW-D. External coil initiation is based on calculations for a proposed DIII-D experiment. In all cases, plasma initiation and preparation of an approximately 0.3 MA plasma for ARIES-ST appears entirely feasible.

A ramp-up scenario for increasing the current from 0.3 MA to the final $31 \mathrm{MA}$ was developed and is illustrated in Fig. 2-1. In order to avoid axisymmetric instabilities, the discharge starts with a small, approximately circular cross-section, limited at the outboard side. The minor radius is increased (and aspect ratio is reduced) until the plasma fills the width of the reactor (at about $10 \mathrm{MA}$ current). Subsequently the elongation is raised to the final value of 3.4. If the confinement is assumed to be standard $\mathrm{H}$-mode throughout, a peak power of $120 \mathrm{MW}$ is needed. Restricting the external power to $50 \mathrm{MW}$ leads to a requirement for confinement control, raising the confinement multiplier by as much as $50 \%$ over $\mathrm{H}$-mode during the ramp-up. Most of the current is provided by bootstrap current (rising from $50 \%$ at the start of the ramp to $100 \%$ at the end).

A study of the influence of shaping on ARIES-ST performance indicates that significant improvement in kink and ballooning stability can be obtained by modest changes in the squareness of the plasma. In test equilibria, the ballooning beta limit is increased from $58 \%$ to $67 \%$. Also the maximum allowable plasma-wall separation for kink stability can be increased by $30 \%$. 
A brief transport analysis showed that, if the ion thermal transport is assumed to behave neoclassically, the ignition condition is maintained if the electron thermal diffusivity exceeds the ion value by a factor of $150-500$, depending on the density profile. The lower value is found for the profiles being used in the ARIES-ST study.

\section{MEETINGS}

The results of this work were presented at an ARIES-ST team meeting at PPPL in September 1998, and also at the IAEA TCM on Spherical Tokamaks at the University of Tokyo in October 1998.
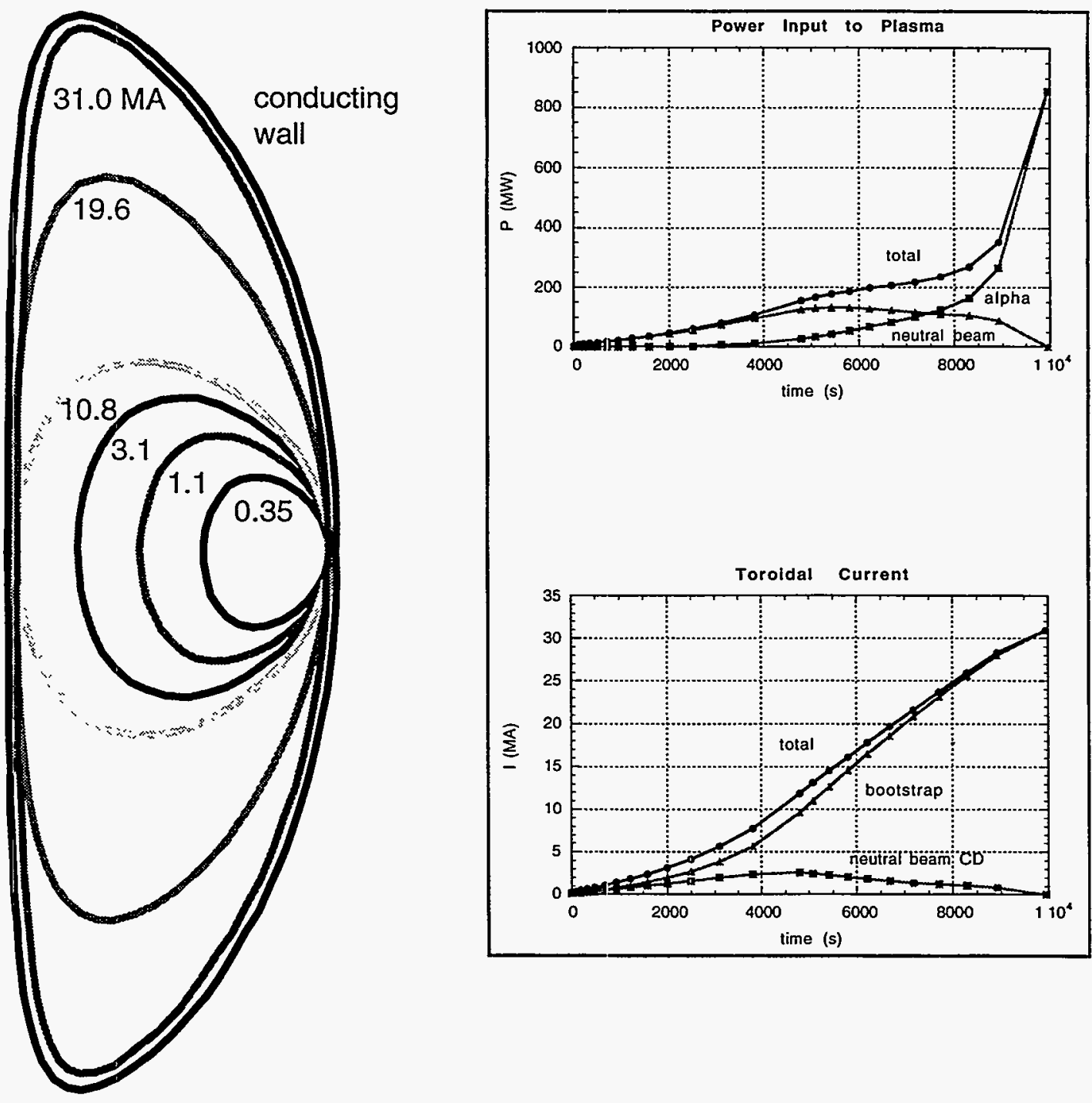

Fig. 2-1. ARIES-ST ramp-up scenario. 


\section{Section 3}

\section{PLASMA INTERACTIVE MATERIALS}




\section{PLASMA INTERACTIVE MATERIALS}

The Divertor Materials Exposure System (DiMES) was used to expose samples to detached plasma, attached plasma, high heat flux plasma, and disruptive plasma. Dust formation studies continued.

Two coated samples were exposed to detached plasma at the outboard divertor and one coated sample was exposed in the private flux region. Discoloration observed on the sample surface indicated uniform deposition. Chemical sputtering is at least a factor of five lower than expected from ion beam experimental results. No erosion or arc track was seen on the tungsten coating in the case of the detached plasma exposure.

A coated sample was exposed to attached plasma with a surface heat flux of $2 \mathrm{MW} / \mathrm{m}^{2}$ at the outboard strike point. The erosion rate of carbon as shown in Fig. 3-1 further supports our projection of carbon to be about 10 times higher than used in ITER calculations. A substantial portion of the beryllium coating was eroded and the tungsten film showed many radial arc tracks. SEM pictures showed details of the radial arc tracks on $0.1 \mathrm{~mm} \mathrm{W-film} \mathrm{on} \mathrm{graphite} \mathrm{samples} \mathrm{exposed} \mathrm{to} \mathrm{attached} \mathrm{plasma} \mathrm{as} \mathrm{shown} \mathrm{in} \mathrm{Fig.} \mathrm{3-1.}$ Most of the tungsten-coating on the arc-track was removed.

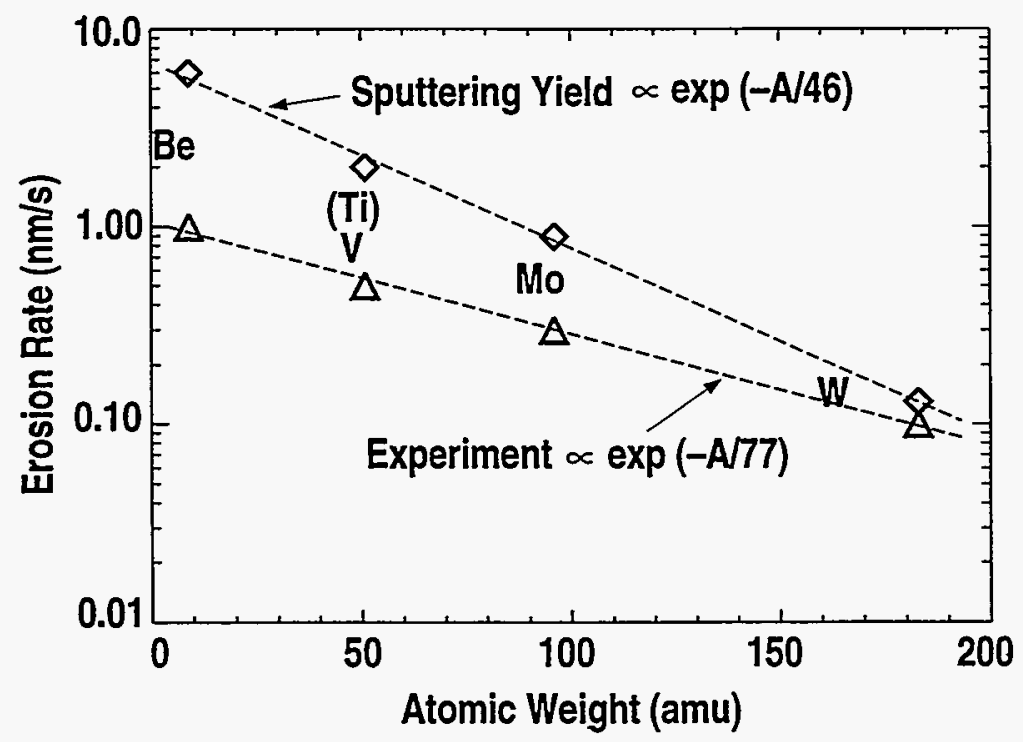

Fig. 3-1. Measured erosion rate of Be, V, Mo and W, at a heat flux of $0.7 \mathrm{MW} / \mathrm{m}^{2}$ and $\mathrm{T}_{e}=45-70 \mathrm{eV}$. Also shown is the gross sputtering rate calculated from the measured ion flux and electron temperature, assuming an incident energy of $3 k T_{e}$. Since no data were available for $V$, the sputtering yield of $T_{i}$ was used. 
An aluminum-coated sample was exposed to a vertical disruption, discrete aluminum was removed and small droplets were observed. SEM pictures taken at SNL showed the complete melting of the $10 \mathrm{~mm}$ Al-layer, but tiny beads of Al essentially remained inplace. This can possibly imply the rapid local heating and condensation of the melted layer.

A dust collection sample with a lip was exposed to heat flux of $\sim 50 \mathrm{MW} / \mathrm{m}^{2}$. SEM showed 5-10 globules. Dust particles of 1-10 mm size were collected. These samples were sent to TRINITI (Troitsk, Russia) for examination.

We supported several ITER design review meetings, completed the preparation of the DiMES section of the final ITER report, proposed an outboard DiMES station for DIII-D and a DiMES like mechanism to NSTX. We modified and repaired the central conductors of DiMES to allow heating of the exposed surface and for instrumentation of the sample. The system was re-installed and the tiles and sample were re-aligned and ready for the next machine-running period of DIII-D.

\section{MEETINGS}

1. C.P.C. Wong attended the ICFRM-8 meeting in Sendai, Japan, October 26, 1997.

2. D.G. Whyte and C.P.C. Wong attended the U.S./Japan PMI/PSI workshop on December 8-11, 1997 in San Francisco, and made presentations on the DiMES accomplishments in 1997.

3. C.P.C. Wong and D.G. Whyte attended the IEA Tritium workshop, March 16-18, 1998 and ITER PFC Erosion and Tritium Inventory and Control meeting, March 19-20, 1998 at PPPL.

4. C.P.C. Wong and D.G. Whyte attended the 13th PSI meeting in San Diego, May 17-22, 1998.

5. C.P.C. Wong attended the Japan-U.S. Workshop on HHFC and PSI for Next Fusion Devices (FT5-01 98) at NIFS/Toki, Japan, October 26-28, 1998.

\section{PUBLICATIONS}

C.P.C. Wong et al., "Divertor Materials Evaluation System (DiMES)," presented at the ICFRM-8 meeting in Sendai, Japan, October 1997.

D.G. Whyte et al., "Divertor Erosion in DIII-D," presented at the 13th Plasma Surface Interaction (PSI) meeting in San Diego, May 1998. 
Section 4 RADIATION TESTING OF ITER MAGNETIC COIL 


\section{RADIATION TESTING OF ITER MAGNETIC COIL}

Discussions were held with Tatsuo Shikama on a collaboration for radiation testing of a magnetic coil in the JMTR reactor. Based on those discussions a conceptual design of a coil was made, fabricated and shipped to Japan for final assembly.

Two ceramic bobbins, with two coils each, and three thermocouples, were built based on the GA design. Three $\mathrm{MgO}$ cables with varying center conductor diameters $(0.25,0.5$, $0.75 \mathrm{~mm}$ ) were used along with a single $\mathrm{Al}_{2} \mathrm{O}_{3}$ cable. Both the U.S. (GA) long pulse integrator (LPI) and the Japanese (JT-60) long-pulse integrators were used in the radiation test on the JMTR reactor. The test is planned for December-January of 19981999.

A new version of the GA LPI was designed and is currently being fabricated for the experiment in Japan. Additional circuitry was added to the test suite of hardware to allow improved monitoring of the Radiation Induced Electro-Motive Force (RIEMF) over prolonged exposure of the mineral insulated wire coils to neutron fields. A preliminary test plan was prepared and is undergoing internal review. When the internal review is completed, the plan will be forwarded to the JMTR team for comment.

\section{MEETINGS}

1. Joint Japan/U.S. meeting on Radiation Tests on Diagnostics, Japan, March 1998.

2. ITER Radiation Effects Meeting, Garching, Germany, June 1998. 

Section 5

RF TECHNOLOGY 


\section{RF TECHNOLOGY}

\section{COMMISSIONING AND TESTING OF S/N \#3R2}

This task was for the commissioning and testing of the S/N 3R2 $110 \mathrm{GHz}, 1 \mathrm{MW}$ gyrotron with a CVD diamond window. Analyses showed that the CVD diamond window should allow full $1 \mathrm{MW} \mathrm{cw}$ operation. The earlier $110 \mathrm{GHz}$ tube had utilized a doubledisc sapphire window that was face-cooled with FC-75 fluorocarbon coolant. This window was limited to $450 \mathrm{~kW} \mathrm{cw}$ or $1 \mathrm{MW}$ for $800 \mathrm{~ms}$ pulse duration. An added advantage of the CVD diamond window is that the output mode can be a fundamental Gaussian rather than the "flattened" Gaussian that was used on the earlier tube. This greatly simplifies the coupling of the output power to a low loss transmission line outside the tube.

The gyrotron S/N 3R2 was successfully rebuilt in May 1998. The gyrotron was then conditioned, with peak power levels of $940 \mathrm{~kW}$ and time average power levels of $80 \mathrm{~kW}$ being achieved. Under long pulse length testing, $650 \mathrm{~kW}$ for $1.6 \mathrm{~s}$ was achieved with the pulse length being limited by arcing in the dummy load rather than any limit identified in the gyrotron. The maximum temperature increase observed on the window surface was $40^{\circ} \mathrm{C}$ at the end of the $1.6 \mathrm{~s}$ pulse, thus the ability of the window to handle $1 \mathrm{MW}$ pulses is almost guaranteed. Testing of the gyrotron at CPI was completed by mid-July 1998 . The gyrotron test parameters achieved at CPI were at the limits of the CPI test apparatus, so further long pulse testing at high power will be carried out at GA.

\section{COMBLINE ANTENNA}

This task covers the relocation of the combline antenna in JFT-2M in order for the antenna to match the new plasma configuration being planned for next year's operating period. Discussions were carried out with T. Ogawa of JFT-2M on the relocation of the combline antenna within the JFT-2M tokamak. After several studies it was determined that $95 \mathrm{~mm}$ was the lowest profile for the antenna and JFT-2M has agreed to set the plasma limiters at $100 \mathrm{~mm}$. The parts needed to relocate the antenna were designed, fabricated, and sent to JFT-2M at the end of September for the scheduled October vent. 


\section{MEETING COORDINATION}

The scope of this task is to coordinate the next U.S./Japan Technology Exchange meeting which is to be held in conjunction with the New Orleans APS meeting in November. Arrangements have been made to hold the meeting November 12 and 13, 1998. Selection of participants has been agreed upon, abstracts for the meeting are forthcoming, with thought being given to future mutually beneficial potential collaborations. 
Section 6 ADVANCED LIQUID PLASMA FACING SURFACES 


\section{ADVANCED LIQUID PLASMA-FACING SURFACES}

We completed the planned activities of supporting the physics task and the study of innovative divertor design approaches. GA coordinated the physics input of the ALPS program-planning document. We accepted the responsibility of coordinating and organizing the physics and plasma material interaction task of edge transport, erosion and redeposition. This is an important and difficult area. Results from this area of work will indicate how the evaporated and/or eroded material would limit core performance, and subsequently impacts the ability of heat removal by the liquid surface at the divertor. Results will be obtained by relying on analysis, bench marking of experimental results and modeling projections.

We presented preliminary results on the radiation of lithium from the core plasma. The major impact is from fuel dilution. As an example, the fusion power of a $6000 \mathrm{MW}$ low aspect ratio reactor could be reduced by a factor of two with a lithium fraction of $10 \%$, which corresponds to a lithium introduction rate of $12 \mathrm{mg} / \mathrm{s}$. Therefore the transport of lithium from the first wall cannot be very high. We also showed that the allowable rate of fluorine injection to the plasma is similar to lithium. We presented the helium-cooled stagnant lithium divertor concept to handle the intense power density from ELMs and disruptions. The droplet divertor concept proposed by GA was also discussed as an innovative divertor design option. We plan to use the DiMES mechanism to study the transport and erosion of lithium in the plasma chamber in 1999. MHD effect on the lithium surface will also be studied.

\section{MEETINGS}

1. GA hosted the ALPS project meeting on February 18-20, 1998 at General Atomics.

2. C.P.C. Wong attended the 5th Japan/China workshop on Materials for Advanced Energy Systems and Fission and Fusion Engineering in Xian, China, November 2-6, 1998 and presented a paper on "APEX and ALPS, High Power Density Technology Program in the U.S.". 


\section{PUBLICATIONS}

C.P.C. Wong, M. Abdou, R. Mattas, "APEX and ALPS, High Power Density Technology Programs in the U.S.," the 5th Japan/China workshop on Materials for Advanced Energy Systems and Fission and Fusion Engineering in Xian, China, November 2-6, 1998. 
Section 7

\section{ADVANCED POWER EXTRACTION STUDY}




\section{ADVANCED POWER EXTRACTION STUDY}

We participated in the identification of critical issues and development requirements for the APEX program. Functional requirements of the helium-cooled first wall, blanket and divertor design were developed and presented. We also assisted in the development of the selection criteria for different concepts for the APEX program. GA and Sandia will coordinate the development of the helium-cooled blanket design, for an average neutron wall loading $>8 \mathrm{MW} / \mathrm{m}^{2}$ with a corresponding surface loading of $>2 \mathrm{MW} / \mathrm{m}^{2}$. We led the assessment and design of the helium-cooled, nested shell, V-alloy $\left(\mathrm{T}_{\max }<700^{\circ} \mathrm{C}\right)$ structural material first wall and blanket design. We found that the design, at a helium pressure of $18 \mathrm{MPa}$ can handle a neutron wall loading of $>10 \mathrm{MW} / \mathrm{m}^{2}$. Based on the encouragement that high temperature, but higher activation, Ta-alloy and $\mathrm{W}$-alloy ( $\mathrm{T}_{\max }$ @ $>1200^{\circ} \mathrm{C}$ ) may also be suitable for fusion application, we initiated the application of these alloys. Preliminary results indicate that $\mathrm{W}$-alloy allows the highest performance first-wall-blanket design for the helium-cooled concept at a coolant pressure of $8 \mathrm{MPa}$.

\section{MEETINGS}

1. C.P.C. Wong organized and participated in the Japan/U.S. Fusion High Power Density Workshop in Sendai, Japan, October 20-22, 1997.

2. C.P.C. Wong attended the UKAEA organized 6th IAEA Technical Committee Meeting on Fusion Power Plant Design and IEA fusion safety and environment meetings at Culham, England, March 24-27, 1998.

\section{PUBLICATIONS}

C.P.C. Wong, "A helium-cooled blanket design for the low aspect ratio reactor," the 6th IAEA Technical Committee Meeting on Fusion Power Plant Design, Culham, England, March 1998. 